—Published in: 'Why Making No Difference Makes No Moral Difference', in: K. Marker, J. Sirsch and A. Schmitt (eds.) Demokratie \& Entscheidung. Wiesbaden: Springer VS (2019): 231-244_-

This is the penultimate draft. For the definitive text, please consult the published version: bttps:/ / link.springer.com/chapter/10.1007/978-3-658-24529-0_15.

For an elaboration of this argument, please see my 'The Moral Arbitrariness of Making No Difference'.

\title{
Why Making No Difference Makes No Moral Difference
}

\section{Christine Tiefensee}

\begin{abstract}
Ascribing moral responsibility in collective action cases is notoriously difficult. After all, if my individual actions make no difference with regard to the prevention of climate change, the alleviation of poverty, or the outcome of national elections, why ought I to stop driving, donate money, or cast my vote? Neither consequentialist nor non-consequentialist moral theories have straightforward responses ready at hand. In this contribution, I present a new suggestion which, based on thoughts about causal overdetermination along the lines of Mackie's INUS account, aims to show that causally overdetermined collective action cases are morally arbitrary in a way that makes it possible to ascribe moral responsibility even if individual actions make no difference.
\end{abstract}

Keywords Collective action $•$ Moral responsibility $\bullet$ Causal overdetermination $•$ Public goods

\section{Introduction}

Charles loves his old, clattering gas guzzler of a car, which he uses for lengthy drives whenever he has a spare moment. Being as eco-conscious as we are, we approach him to point out the great threat posed by climate change and implore him to refrain from this wasteful and polluting hobby. Charles has read some climate reports himself but responds: It makes no difference to climate change whether or not I drive, so I have no reason to give up driving.

Elizabeth is acutely aware of the great suffering in the world and much aggrieved by the severe deprivation that millions of people endure. Accordingly, we provide her with information about several relief organisations, all of which collect money to alleviate world poverty. She expresses her genuine thanks to us, but answers: It makes no difference to the fight against world poverty whether or not I make a small donation, so I have no reason to give away my money.

Philip has been following the news about the current election campaign between two candidates, Jones and Smith. It is clear that if elected, Jones will have an extremely damaging effect on the country's cohesion, prosperity and reputation, yet he is never- 
theless ahead in the polls. Being desperate to prevent Jones from winning, we urge Philip to cast his vote for Smith. Philip clearly shares our concerns, yet remarks: It makes no difference to the election outcome whether or not I vote for Smith, so I have no reason to cast my vote.

Charles, Elizabeth and Philip appear to be right: Their respective individual actions make no difference with regard to the occurrence of climate change, world poverty and election results. Still, many will agree that Charles, Elizabeth and Philip all have moral reason to give up leisure drives, donate to charity and vote. My aim in this contribution is to explain why. ${ }^{1}$

I start by explicating the specific structure of the decision-situations that underlie the 'no difference' argument which, in turn, concerns the problem of how to ascribe moral responsibility in collective action cases characterised by causal overdetermination (\$2). I will then briefly consider different strategies to tackle this problem (\$3). My own suggestion will be presented in (\$4). Drawing on John Mackie's INUS account, this aims to show that causally overdetermined collective action cases are morally arbitrary in a way that makes it possible to ascribe moral responsibility even if individual actions make no difference. I conclude with some general remarks in $(\$ 5)$. For the rest of this paper, I will limit my focus to the case of climate change.

\section{Clarifying the problem: collective action and the 'no difference' argument}

Let us return to Charles and his gas guzzler, then, and consider which features of his specific decision-situation contribute to the response that his individual actions have no impact on the occurrence of climate change.

The first is obvious: Granting that climate change is at least partly caused by human activities, it is the unintended, aggregated effect of a large amount of individual actions. As such, individual behaviour, such as Charles' pleasure drives, is neither necessary nor sufficient for climate change: It is not necessary because climate change will occur even if Charles abandons his drives, provided that a sufficient number of other agents do not change their behaviour. It is not sufficient because climate change would not occur if Charles were the only person who kept driving, whereas all others changed their respective behaviour. Consequently, climate change falls within the class of collective action cases: Just as it is collective action that causes climate change, it is collective action that would need to change so as to solve environmental problems.

Secondly, although climate change concerns a collective action problem, we are neither dealing with a group agent nor joint action. That is, individuals do not combine into some collective agent to which propositional attitudes and a stable identity could be ascribed, nor do they act with some shared intention, such as going for a drive to-

1 Although preventing climate change, fighting world poverty and electing political representatives fall into the domain of collective action, they also show important differences which are likely to necessitate somewhat different approaches to their moral assessments. As I will focus only on climate change, I will neglect these subtleties here. 
gether. Rather, Charles is a member of a mere collection or aggregate of agents, all of whom simply go about their own business without being connected through shared intentions or organisational structure.

Thirdly, the collective action problem of climate change is characterised by causal overdetermination. Causal overdetermination occurs when there are several sufficient and distinct causes for the same event. For instance, if you are ill and simultaneously take two different sorts of medication, where each one of these would have been sufficient to cure your disease, your recovery is causally overdetermined. Climate change, too, is such a causally overdetermined event: Although climate change would have been caused by a certain number of specific individual actions, many more such actions are performed than would have been required for triggering this effect.

Given as much, we can summarise Charles' basic decision-situation as depicted in the following, admittedly oversimplified matrix (Fig. 1):

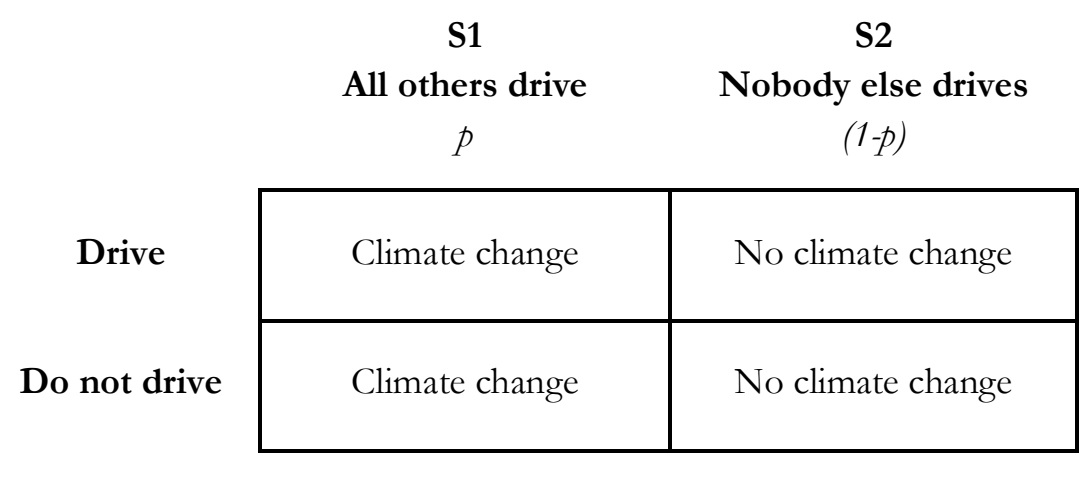

Fig. 1: Charles' basic decision-situation

As this matrix shows, no matter which action Charles chooses, the outcome will be the same: In (S1), climate change will occur; in (S2), it will not-independently of Charles' decision to drive or abstain from driving. Charles' actions, then, simply do not make a difference with regard to climate change.

When examining collective action problems, we are often interested in the instrumental rationality of decisions. Collective action dilemmas in particular attain their philosophical explosiveness because it can be shown to be individually rational to perform an action that contributes to collectively suboptimal results. However, the 'no difference' argument does not concern the rationality of Charles' actions, but their moral status: It pertains to moral reasons, and not any prudential considerations, for Charles to change his behaviour. As such, this argument can be explicated as follows:

(P1) If $\Phi$-ing makes no difference with regard to effect $E$, the occurrence of $E$ provides no moral reason to refrain from $\Phi$-ing.

(P2) Charles' driving makes no difference with regard to climate change.

(C) Hence, the occurrence of climate change provides no moral reason for Charles to refrain from driving. 
Hence, if you agree with the assessment that Charles does have a moral reason to give up his pleasure drives, we must find a way to reject this argument. As I will explain in the next section, I believe that we should do so by attacking (P1), not (P2). Consequently, we face the following challenge: We must be able to show that Charles has a moral reason to refrain from pleasure driving although his actions, albeit causally efficacious, make no difference to the occurrence of the causally overdetermined collective action effect of climate change.

I believe that we can successfully discharge this task. Before I explain how, though, let me briefly mention alternative strategies for reacting to the 'no difference' argument and why I will not pursue them.

\section{Alternative responses}

There are various ways in which we could respond to the 'no difference' argument. The three main strategies are as follows:

1. Bite the bullet. We could accept the conclusion that there is no moral reason for Charles to stop driving, yet deny that this is a problem. ${ }^{2}$ For instance, it could be argued that although Charles himself has no moral reason to change his individual behaviour, the group of drivers or the government still have a moral responsibility to change behaviour or introduce legislation that will impact on people's actions such that climate change is halted. At least at first sight, this approach appears quite plausible: Since we are dealing with a collective action problem, and not individually harmful actions, it does not seem far-fetched to locate moral responsibility on the collective rather than individual level.

However, pointing to the group of agents to which Charles belongs is not a very promising strategy. As stated above, this collection cannot be understood as a group agent, but must be regarded as a mere aggregate of individuals. It is by no means clear, though, how moral responsibility is supposed to be ascribed to such an aggregate of agents. Moreover, even if we could make sense of collective responsibility in cases such as these, collective responsibility cannot be straightforwardly translated into individual obligations that Charles, for instance, would need to discharge.

Appeal to governments' roles within this collective action case is more hopeful, but still not satisfying. Firstly, calling on governments to introduce legislation that will disincentivise actions such as driving is likely to involve penalising the respective individual actions. Since this response to the 'no difference' argument does not regard these individual actions as morally problematic, though, the question is on which grounds such government intervention can be justified. Secondly, the same 'no difference' argument can be repeated on the higher level of governments, as individual states can point out that their national legislation makes no difference in solving the international problem of climate change. The present strategy offers no response to this variation on the 'no difference' argument. Thirdly, shifting responsibility attributions from individu-

\footnotetext{
2 Compare Sinnott-Armstrong (2005) for an argument along these lines.
} 
als to governments cannot capture the strong intuition that individual agents do have a moral reason to change their behaviour in cases of collective harms. Although governments are likely to play a significant role in the solution of collective action problems, then, it would be desirable if morality had more to say about Charles' individual actions, rather than just those of collective agents such as states. Biting the bullet, then, is no option.

2. Making a difference: Alternatively, we could deny (P2) and argue instead that Charles' actions do make a difference with regard to climate change. Admittedly, the harm generated by Charles' pleasure rides might be miniscule, even imperceptible. Nevertheless, it exists: Charles' actions do make climate change worse, even if indiscernibly so. ${ }^{3}$

Now, there might be collective action situations-so-called 'triggering' cases-in which individual actions do indeed matter. For instance, return to the election between Jones and Smith and assume that the electorate comprises 100 voters, all of whom cast valid votes. Assume further that 50 voters have already voted for Smith and 49 for Jones. In this case, Charles' additional vote for Smith would make a difference in securing Smith's election (Fig. 2):

S1

70 vote for Smith

$p_{1}$

\begin{tabular}{|c|c|c|c|}
\cline { 2 - 3 } $\begin{array}{c}\text { Vote for } \\
\text { Smith }\end{array}$ & Smith wins & Smith does not win & Smith wins \\
\cline { 2 - 4 } $\begin{array}{c}\text { Do not vote } \\
\text { for Smith }\end{array}$ & Smith wins & Smith does not win & Smith does not win \\
\cline { 2 - 4 } & &
\end{tabular}

Fig. 2: Voting as a triggering case
S3

50 vote for Smith

$p_{3}$
20 vote for Smith

$p_{2}$

However, such triggering situations clearly are the exception, rather than the rule. For instance, we can be pretty sure that Charles' pleasure driving has neither triggered climate change as such, nor added another degree of temperature to global warming. This is not to deny, of course, that Charles' driving impacts on the overall amount of greenhouse gases emitted. It does. Nor is it to deny that there might be a risk of being a trigger, even if this risk might be negligible. Yet, it is to deny that the miniscule amount of $\mathrm{CO}_{2}$ emissions caused by Charles constitutes a form of harm. The concept of an imperceptible harm is not plausible. As such, (P2) stands firm.

3. Deontology: Finally, we could tackle (P1), and thus reject the claim that we have a moral reason to perform or refrain from some action only if this action makes a difference with regard to some outcome. One way to do so would be to adopt a specifically

${ }^{3}$ For imperceptible harms, see Parfit (1984). For triggering cases and risk-based analyses, see Kagan (2011). For an excellent discussion of these suggestions, see Nefsky (2012). 
deontological moral theory. That is, it could be argued that the problem of ascribing moral responsibility in collective action cases is not one for morality as such, but only one for particular moral theories, namely those advocating consequentialism. After all, consequentialism evaluates moral actions on grounds of their consequences: Simplifying considerably, it judges that actions are permissible if their consequences are good; if their consequences are harmful, they are impermissible. However, in cases such as Charles' hobby, his individual actions do not cause any harm. As a result, consequentialism appears to have no means in order to condemn them. Given as much, the obvious solution might be to leave consequentialism behind and turn to deontological moral theories instead. ${ }^{4}$ Since these do not regard consequences as the only morally relevant features of an action, they might have better chances of justifying why Charles should stop driving his beloved car for fun even if the individual consequences of this action are not harmful.

Although this response sounds straightforward, it is surprisingly difficult to spell it out convincingly. For instance, adopting a Kantian approach, it is not unlikely that we can formulate the maxim on grounds of which Charles acts in such a way that renders his pleasure drives universalisable. Moreover, it is not clear how the actions of others, which inevitably need to be considered in collective action cases, can be included in the individual maxims which underlie individual actions. However, I do not mean to imply here that no persuasive deontological reply to the 'no difference' argument can be developed. Rather, I am more interested in considering whether or not a consequentialist response would also be available. Were consequentialism unable to provide such a response, the 'no difference' argument would take on an even greater significance, in that it could now be fielded in support of deontology and against consequentialism. In order to know whether or not the argument can be so used, though, we first need to find out whether or not consequentialists can deal with the challenge it poses. Accordingly, my contribution can be understood as making a start in providing an answer to this question.

Where does that leave us? I have said that we should aim to reject the 'no difference' argument. At the same time, I have suggested that we should not bite the bullet, nor postulate the existence of imperceptible harms, nor turn to deontology (as yet) in order to rebut it. What strategy remains, then?

I believe that in line with the deontological response, we should target (P1). In contrast to this response, though, we should remain within a consequentialist framework. More precisely, we should aim to reject the direct inference from making no difference to the non-existence of moral reasons by denying that making no difference determines the moral status of actions from a consequentialist perspective. This strategy will concern us for the remainder of this contribution.

${ }^{4}$ For a modified Kantian approach, see Parfit (2011). For a discussion thereof, see Albertzart (Ms.). 


\section{Why making no difference makes no moral difference}

The 'no difference' argument is part of a wider debate about moral responsibility and causation: When examining the role of Charles' actions in bringing about climate change, we are considering whether or not we can hold him morally responsible for this great harm. At the same time, appeal to making a difference clearly hints at the relevance of the causal effects that Charles' actions may or may not have, pointing out that they are sufficient neither for bringing climate change about nor preventing it. Let us simply grant here that some link between moral responsibility and causation is plausible, although this will inevitably be complex. Given as much, my case against the 'no difference' argument will comprise two steps. Firstly, I will explain in which way Charles' actions can be regarded as being a part of the cause of climate change. Establishing as much, though, is not enough to rebut the 'no difference' argument. For, the challenge posed by this argument is not to explain how Charles' driving can be regarded as being part of the cause of climate change, but how Charles can have a moral reason to change his actions, even though his actions make no difference despite being part of the cause. As a second step, I will thus address this challenge by arguing that the account of causation appealed to in the first step makes possible an analysis of causally overdetermined collective action cases which shows this causal analysis to be morally arbitrary in a way that undermines the 'no difference' argument.

Starting with the former, it is clear that if we want to rebut the 'no difference' argument, we cannot draw on a simple counterfactual account of causation, according to which some event $A$ causes an event $C$ only if it is true that if $A$ had not occurred, $C$ would not have occurred. Since Charles' actions do not satisfy this simple counterfactual condition, we need instead a theory of causation which allows us to classify $A$ as a cause of $C$ even if $C$ might have occurred without $A$ obtaining. ${ }^{5}$ John Mackie's (1965) INUS account is one such theory which makes this possible. ${ }^{6}$ According to Mackie, causes are (at a minimum) INUS conditions, in that they must be Insufficient but Necessary parts of a condition which is itself Unnecessary but Sufficient for some effect. For instance, assume that there are two different explanations for the rise of populist parties: According to one, populism is strengthened if economic growth stagnates and welfare payments are cut; according to the other, support for populism rises if fear of other cultures is high and migration has increased. Let us focus on economic stagnation, although we could also have picked any of the other variables. Economic stagnation is Insufficient for the rise of populism, as populism would not increase if the economy stagnated, but welfare payments remained untouched. At the same time, it is a

${ }^{5}$ Goldman (1999) also refers to INUS conditions, whereas Braham/van Hees (2012) refer to related NESS conditions to deal with the 'no difference' argument in collective action cases. I believe that both, though, underestimate the challenge posed by the 'no difference' argument for the reasons provided by Nefsky (2012: 73, fn. 128).

${ }^{6}$ Hence, I merely use Mackie's theory as one example of such a theory. Any other causal theory which makes it possible to classify $A$ as a cause of $C$ even if $C$ might have occurred without $A$ obtaining should also be employable at this stage. 
Necessary part of the condition combining economic stagnation with welfare cuts, as welfare cuts without coinciding economic stagnation would not lead to stronger populist parties. This condition, in turn, is itself Unnecessary, as populism would also have been strengthened if fear of others and migration levels were high. Yet, it is Sufficient: If economic growth stagnates and welfare payments are cut, support for populism will grow, no matter whether or not any other variables obtain. Consequently, economic stagnation is an INUS condition, and thus a cause of rising populism, although populism may have risen even if economic growth had not been flat.

Now, as the second premise of the 'no difference' argument makes plain, Charles' pleasure driving is certainly neither necessary nor sufficient for climate change. But is it an INUS condition for this effect? Two responses are possible. Firstly, we could argue that climate change is caused by a large set of individual actions, of which Charles' pleasure driving is only one component (see Fig. 3):

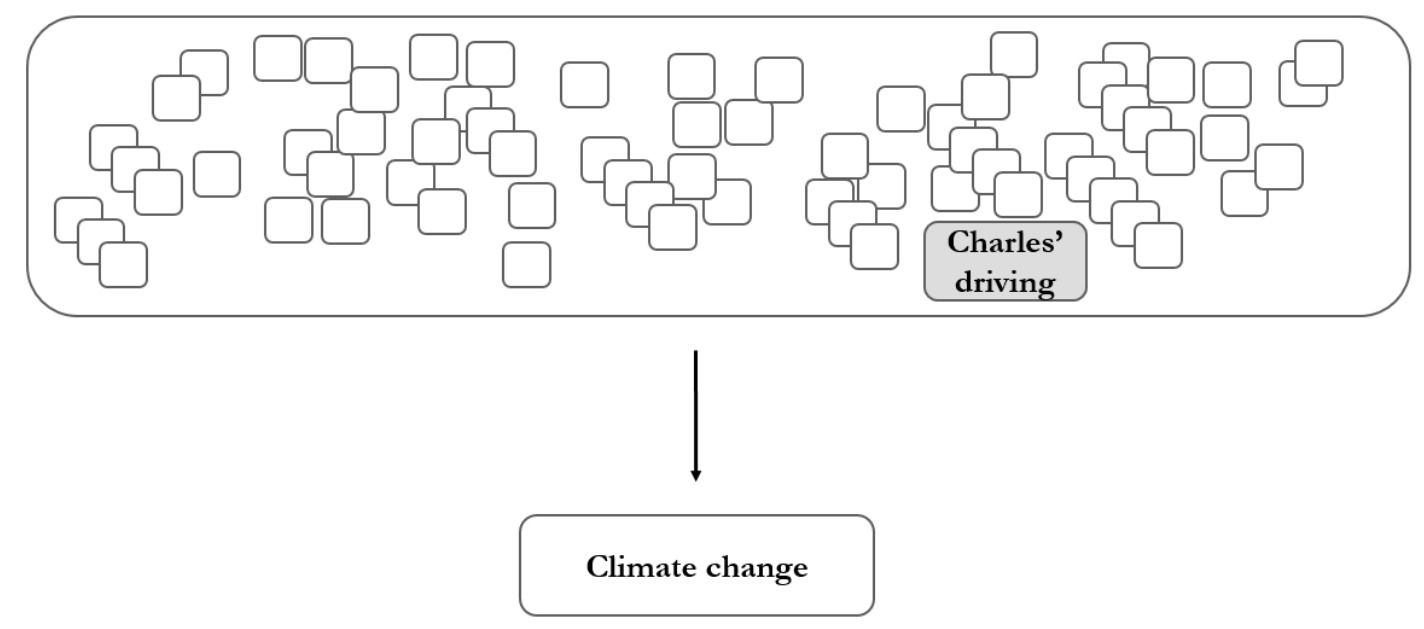

Fig. 3: Causal analysis 1_Charles' driving is no INUS condition

If this were the right analysis of the situation, Charles' actions would not be a necessary part of this set-if he stopped driving, the remaining actions would still be jointly sufficient to bring about climate change-, and thus would not qualify as an INUS condition and part of the cause of climate change. However, nor would any of the other actions in this set qualify. For, although we have singled out Charles' driving here, there is, after all, nothing special about his actions - rather, we could just as well have picked any other individual action in this set and come to the same conclusion. Consequently, since none of the actions in this vast set is necessary, none would qualify as an INUS condition, which means that climate change would have no causes. This seems utterly implausible. The graph depicted in Figure 3, then, cannot be the right causal analysis of climate change.

A second approach delivers more plausible results. This compartmentalises the big set of actions from Figure 3 into smaller sets, where the size of each smaller set is de- 
termined by a sufficiency constraint such that it contains the exact number of actions required for bringing about climate change (Fig. 4): ${ }^{7}$

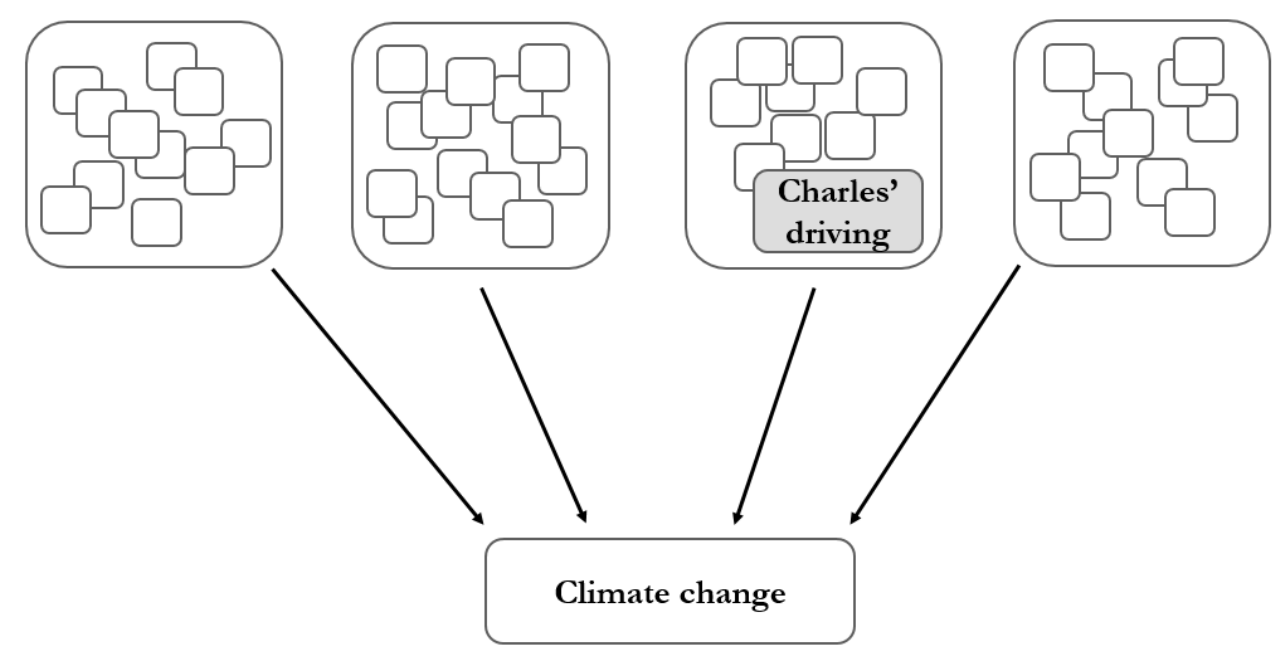

Fig. 4: Causal analysis 2-Charles' driving as an INUS condition

If analysed along the lines of Figure 4, Charles' actions would qualify as an INUS condition for climate change: His actions are now necessary for the specific set, since the set's remaining actions would no longer be jointly sufficient for climate change, were he to stop driving. Hence, despite being neither individually necessary nor sufficient, his driving would be a necessary part of a sufficient but unnecessary set of actions, as there are also other sets of actions which could have caused climate change. As such, we can conclude that Charles' driving qualifies as a cause of climate change despite making no difference. Step 1 of the argument is complete.

As a second step, then, we need to explain how Charles can have a moral reason to change his actions even though these make no difference with regard to climate change despite being part of its cause. One way to do so would be to show that an act can assume a morally significant, non-superfluous causal role despite not making a difference. An action performing this role, we can say, 'helps' bring about a result. ${ }^{8}$ As such, we would need to introduce a new distinction amongst actions, filtering those that help bring about a result and are part of its cause from those that are causally efficacious, but not helpful. However, even if this suggestion were successful, it would thus come with the theoretical cost of adding a new property, namely that of helping, to the orthodox dimension of causation. Yet, I do not believe that we need to incur this cost in order to rebut the 'no difference' argument. Rather, I will argue next that making do with nothing more than 'good old' causation, based on Mackie's INUS account we can see that cases of causal overdetermination are morally arbitrary in a way that makes possible ascriptions of individual moral responsibility.

${ }^{7}$ Accordingly, the set of compartmentalisations is the set containing all the sets which are sufficient for climate change.

8 This is Nefsky's 2012 solution. 
To see how this proposal works, let us return to Figure 4 and reconsider Charles' basic point that he has no moral reason to change his behaviour since this would have no impact on the occurrence of climate change. As this causal analysis shows, he can put forward such an argument only because other sets of actions exist that are sufficient for climate change-after all, if there were no such further sets, Charles' driving would make a difference as his actions would now be necessary for bringing about this result. Accordingly, were there no other sets at which to point fingers, Charles' attempt to deflect moral responsibility from his own actions would collapse.

This pointing of fingers at other sets, though, is morally arbitrary in an important way. Assume, as a totally stylised toy case, that climate change is triggered if 30 units of $\mathrm{CO}_{2}$ are emitted into the air. Assume further that Charles' pleasure drives emit 10 such units, Elizabeth's 15, Philip's 20 and Harry's 10. Accordingly, we are dealing with the following causal graph (Fig. 5):

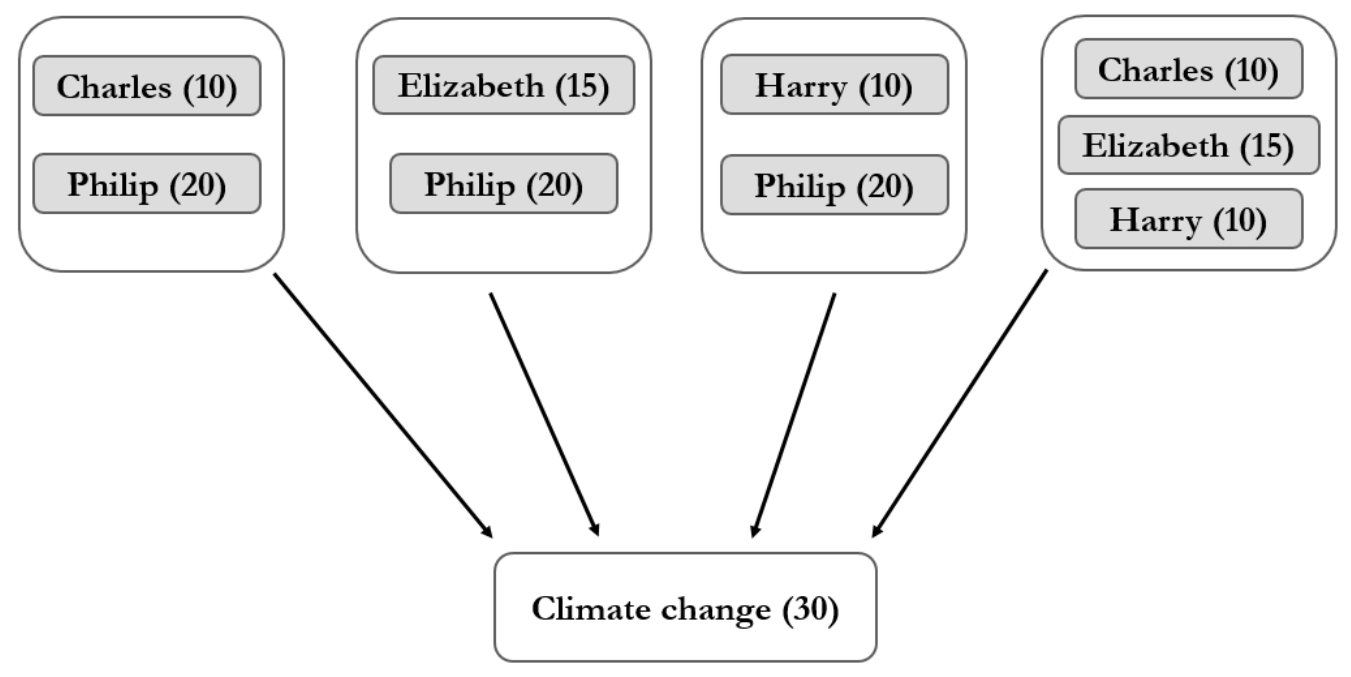

Fig. 5: A toy case of pointing fingers

Finally, assume that Charles repeats his statement that he has no reason to stop driving because doing so would make no difference, given the existence of the two middle sets which do not contain his actions and are sufficient for bringing about climate change.

Charles' attempted deflection of moral responsibility is morally arbitrary, though, in that there is no morally relevant way to distinguish between these separate sets of actions: Since all of them are sufficient for bringing about climate change, they differ only with regard to their specific composition, and thus the question of whose actions they include. That the driving was done by one specific agent rather than another, though, is not morally relevant in the case we are considering. That is, when enquiring into the reasons Charles may or may not have to give up driving, we are not looking for an agent-relative reason which would apply specifically to Charles in light of bis individual interests, his relationships with others, or his prior actions, such as his having promised to stop driving, say. Rather, we are asking for an agent-neutral reason which is not 
indexed to Charles, but applies just as much to Elizabeth, Harry or Philip. ${ }^{9}$ Hence, given that the sets included in Figure 5 differ only with regard to the morally irrelevant fact of who performed the respective action, they are morally indistinguishable: There is no moral basis for our singling out just one of these sets as morally responsible, rather than any of the others. Consequently, Charles' attempt to deflect moral responsibility from the sets that contain his actions to the two middle sets is morally unfounded.

However, there is still a hitch. For, as it stands, this argument from the moral indistinguishability of INUS sets secures the result that given the moral parity of these sets, it would be morally arbitrary for Charles to hold Elizabeth, Philip and Harry responsible for climate change, but not himself. However, it might be thought that it had never been Charles' intention to suggest that everyone but be bimself has a reason to stop driving. Instead, it is more plausible to understand him as claiming that nobody has a reason to change behaviour, exactly because of the analysis provided in Figure 5. Consequently, in order to rebut the 'no difference' argument, the argument from moral indistinguishability must establish that everybody is morally responsible for climate change. However, so far moral parity imposes only the constraint that moral responsibility be attributed either to everybody, or to nobody.

Why, then, should we hold everyone, rather than no one, responsible for climate change if INUS sets are morally indistinguishable? To answer this question, consider first how we would attribute moral responsibility in a case where only one sufficient, and therefore necessary, set of actions for climate change existed. For instance, assume as a first scenario that only the left-hand set of Figure 5 obtained, i.e. that only Charles and Philip drive. If so, we would clearly hold them responsible for climate change, as their actions would now be necessary to bring this result about. Next, add the other sets of Figure 5 as a second scenario. The 'nobody' option would now entail that although Charles and Philip can be held morally responsible in the first scenario, all moral responsibility vanishes in the second. This is not a desirable result. But nor is it plausible. For, why should all moral responsibility evaporate when shifting from the first to the second scenario, just because others are acting in the same way as Charles and Philip, say? Again, the fact that there are further INUS sets is not only contingent, but also appears morally irrelevant, in that it does not detract from the moral responsibility that Charles bears for his own actions and their causal involvement in climate change.

The 'everybody' option, in turn, preserves moral responsibility in both scenarios: Instead of letting the contingent fact of others' acting like Charles eliminate moral responsibility, it expands moral responsibility for climate change to everybody involved in this specific kind of behaviour. Accordingly, the moral parity of INUS sets, combined with the plausible view that moral responsibility cannot be eradicated by the contingent fact that others are acting in similar ways, entails that everybody shares moral responsibility for climate change.

${ }^{9}$ For the distinction between agent-neutral and agent-relative reasons, see Parfit (1984) and Pettit (1987). 
Consequently, the INUS approach to causation enables us not only to classify Charles' actions as part of the cause for climate change. Rather, it also delivers a causal analysis which, when combined with plausible moral views, makes it possible to hold him morally responsible for this result, even though his actions make no difference. As such, pointing out that he himself cannot alter the occurrence of climate change is no good moral excuse. Since he is morally responsible for a great harm, Charles does have a moral reason to abstain from his pleasure drives.

Does this result imply that all agents involved bear exactly the same amount of moral responsibility? Not necessarily. Rather, we can use the analysis provided in figure 5 to assess the moral responsibility borne by each agent based on the number of INUS sets in which his actions feature as well as the size that these INUS sets possess. More precisely, we can define that agent $A$ bears more moral responsibility for some outcome than agent $B$ if $A$ 's actions feature in more INUS sets than $B$ 's, and/or if the INUS sets of which $A$ 's actions are part comprise fewer elements than those in which $B$ 's actions feature. To illustrate, compare the relevance of Philip's and Charles' driving: Philip's actions not only feature in more INUS sets than Charles', but also require fewer supplementary parts so as to secure sufficiency for the respective sets. Since Philip's driving has, therefore, more weight than Charles', we can also attribute greater moral responsibility to him than to Charles.

Does this result entail that whenever we are dealing with collective action cases, everybody engaging in a certain activity is to be held morally responsible for an outcome? Again, this is not necessarily so. To see why, let us add a temporal dimension to climate change and assume that climate change was triggered 40 years ago. If so, Charles' going for pleasure drives now would not be a partial cause for climate change, which also means that he cannot be held responsible for the harm caused 40 years ago. In this case, then, Charles really would have no reason to stop driving. This, though, is no counterexample to the account defended here-rather, it is exactly as it should be. Of course, this assessment would change if climate change, once triggered, could be worsened, say by generating further degrees of global warming. If so, Charles' driving would be part of the cause for this next, more harmful stage of climate change and the analysis provided here would once more apply: Although his actions would make no difference, he would be just as morally responsible for the further harm caused as anybody else engaging in a similar activity.

\section{Conclusion}

The 'no difference' argument has near-ubiquitous application: We encounter it in various situations, contexts and circumstances. Disconcertingly, these situations are usually exactly those that pertain to the most pressing concerns of our time: Climate change, global poverty and national elections are just some examples. Accordingly, it is just as urgent that we develop a convincing retort to this argument, showing that we do have moral reason to change our behaviour even if doing so does not make a difference. 
Based on Mackie's INUS account, I have suggested one such retort, arguing that causally overdetermined collective action cases are morally arbitrary in a way that makes it possible to ascribe moral responsibility, even if individual actions cannot change the occurrence of climate change, global poverty or election outcomes, say. Making no causal difference, then, makes no moral difference.

\section{References}

Albertzart, M. (Ms.) 'Kant and the Problem of Imperceptible Differences'.

Braham, M. \& M. van Hees (2012) 'An Anatomy of Moral Responsibility', Mind 121: 601-634.

Goldman, A. I. (1999) 'Why Citizens Should Vote: A Causal Responsibility Approach', Social Philosophy \& Policy 16: 201-217.

Kagan, S. (2011) 'Do I Make a Difference?', Philosophy \& Public Affairs 39: 105-141.

Mackie, J. L. (1965) 'Causes and Conditions', American Philosophical Quarterly 12: 245-65.

Parfit, D. (1984) Reasons and Persons. Oxford: Clarendon Press.

- (2011) On What Matters, Vol. I. Oxford: Oxford University Press.

Pettit, P. (1987) 'Universality Without Utilitarianism', Mind 72: 74-82.

Sinnott-Armstrong, W. (2005) 'It's Not My Fault: Global Warming and Individual Moral Obligations', in: W. Sinnott-Armstrong \& R. Howarth (eds.) Perspectives on Climate Change: Science, Economics, Politics, Ethics. Advances in the Economics of Environmental Research, Vol. 5. Amsterdam: Elsevier: 293-315. 